\title{
Assistive Robotics and an Ecology of Elders Living Independently in Their Homes
}

\author{
Jodi Forlizzi, Carl DiSalvo, and \\ Francine Gemperle \\ Carnegie Mellon University
}

\begin{abstract}
For elders who remain independent in their homes, the home becomes more than just a place to eat and sleep. The home becomes a place where people care for each other, and it gradually subsumes all activities. This article reports on an ethnographic study of aging adults who live independently in their homes. Seventeen elders aged 60 through 90 were interviewed and observed in their homes in 2 Midwestern cities. The goal is to understand how robotic products might assist these people, helping them to stay independent and active longer. The experience of aging is described as an ecology of aging made up of people, products, and activities taking place in a local environment of the home and the surrounding community. In this environment, product successes and failures often have a dramatic impact on the ecology, throwing off a delicate balance.
\end{abstract}

Jodi Forlizzi is an interaction designer with an interest in the intersection of aesthetic, assistive, and social products; she is an Assistant Professor in the $\mathrm{Hu}$ man-Computer Interaction Institute and the School of Design at Carnegie Mellon University. Carl DiSalvo is a designer with an interest in the relation among agency, the body, power, and design; he is a $\mathrm{PhD}$ candidate in the School of Design at Carnegie Mellon University. Francine Gemperle is an industrial designer with an interest in the human body; she is a Special Research Faculty in the Institute for Complex Engineered Systems at Carnegie Mellon University. 


\section{CONTENTS}

\section{INTRODUCTION}

1.1. Context of Assistive Robotics

1.2. Ethnographic Studies of Aging

2. METHOD

1.3. Ecology of Aging

2.1. Data Sources

2.2. Analysis

3. FINDINGS

3.1. People

3.2. Products

Why Do Elders Want Products?

How Do Elders Use Products?

How Do Products Support Values for the Elder Population?

3.3. Environments

3.4. Activities and Experiences

3.5. Summary of Findings

4. ROBOTIC PRODUCTS TO SUPPORT THE ECOLOGY OF AGING

4.1. Design Guidelines

Robotic Products Must Fit the Ecology as Part of a System

Robotic Products Must Support the Changing Values of Those

Within the Ecology

Robotic Products Must Be Functionally Adaptive

4.2. An Ecological Approach to the Design Process

When a breakdown occurs, family members and other caregivers have to intervene, threatening elders' independence and identity. This article highlights the interest in how the elder ecology can be supported by new robotic products that are conceived of as a part of this interdependent system. It is recommended that the design of these products fit the ecology as part of the system, support elders' values, and adapt to all of the members of the ecology who will interact with them.

\section{INTRODUCTION}

The United States is currently witnessing a rapid increase in the number of elderly people. The U.S. Census (2000) estimated that there will be about 12 million people over age 85 in 2040. Many are expected to need physical and cognitive assistance. Nursing homes and other care facilities can provide some 
assistance, but they already suffer from space and staff shortages. As the elder population continues to grow, the greatest need for assistance will come from elders who live independently in their own homes.

Advanced technology—artificial intelligence, image processing, and speech simulation and speech processing - can be used to help elders and caregivers. To date, many of the breakthroughs in advanced and autonomous technology, such as assistive robotics, have only begun to offer social and economic benefits (Computing Research Association, 2003). These systems are the precursor to tomorrow's assistive robotic products. Even in this early stage, these systems should address the social, emotional, and environmental needs of elders and caregivers. If inappropriately designed, assistive products come at a great cost to society because they will not help those they were designed for and because they will be unused.

Our goal is to aid the design and development of assistive robotic products for the elderly through the development of design guidelines grounded in ethnographic research. In particular, we are interested in supporting elders who wish to remain independent in their homes. Elders are healthier and report a higher quality of life when they are able to stay in their own homes (Lawton, 1982). There are also substantial financial incentives to helping elders live at home rather than in dedicated care facilities. The questions we need to address are whether robotic products are appropriate assistive products to support elders; and if so, how to introduce them into the context of the home.

We define a product, after design historian Victor Margolin (1997), as any of a broad range of artifacts, services, and environments in the world. A future robotic product might be an intelligent information appliance or a system of distributed products and services within one's home. We believe assistive robotic products will exist in elders' homes along with their treasured possessions, mundane appliances, and a variety of assistive products. We aim to understand how robotic products should fit within elders' home environments. A future step will be to assess specific product ideas-appropriate tasks for the product, what form it might take, what materials it might be constructed from, what senses it might engage, and what interactions it might offer. Together, these design decisions will set the right expectations about how a robotic product might be used.

This article reports an ethnography of the daily domestic lives of elders, their living environments, the products and services embedded in those environments, and the activities that elders engage in. We believe that by better understanding elders' current relations to people, products, and activities, we can begin to ask appropriate questions about how future robotic products might fit within the home. 


\subsection{Context of Assistive Robotics}

Technological advances are currently being directed to assist the elder population. These products, which can be charted in the assistive robotics literature, emphasize the independence of the elderly as a primary goal. They provide support for a range of basic activities, including eating, bathing, dressing, and toileting (MOVAID, 2002; RAID Workstation, 2002; RAIL, 2002). They support mobility in the form of ambulation assistance and rehabilitation (GuideCane, 2002; Haptica, 2002; Morris et al., 2002; NavChair, 2002; Wheelesley, 2002). They provide household maintenance in the form of monitoring and maintaining safety in particular environments (Mynatt, Essa, \& Rogers, 2000). However, many of these products have been designed with little consideration of the social, aesthetic, and emotional relations that elders will form with the product. Future assistive robotic products will need to move beyond task-based interactions and be attractive, affordable, and nonstigmatizing. Accessibility, ease of use, and reliability will also be particularly important for aging users.

An example of how people's values can affect their usage of an assistive product may be seen in the case of current mobility aids. Walkers, rollators, and canes assist in mobility for all who use them. For the elder population specifically, these products mediate the activities of daily living, provide opportunities for partaking in social activities, and reduce the risk of falls. Studies of elders have shown that nearly one third of these devices are abandoned within the first 3 months (Guralnik et al., 1993); the disuse rate is as high as 54\% (Scherer \& Galvin, 1994). These products' appearance inhibits many from using them in normal social situations (Hirsch et al., 2000). Elders who do use walkers are inspired by the autonomy they afford; for these people, aesthetic considerations are secondary (Mann, Hurren, Tomita, \& Charvat, 1995).

Roboticists have developed a number of mobility enhancing assistive technologies. Most of these share control over motion with the user, undertaking path navigation and obstacle avoidance (Lankenau \& Röfer, 2001; Mazo, 2001; Prassler, Scholz, \& Fiorini, 2001). The GUIDO (2002) walker provides power-assisted wall or corridor following. The PAMM (Dubowsky et al., 2000) project focuses on navigation for residents in an eldercare facility, adopting a customized holonomic walker frame as its physical form. Although these examples are inspirational, we need to better understand the context that these products will be used in.

Our examination of the emerging field of rehabilitative robotics revealed several opportunities for design research. The home is a growing area of need. Many debilitating accidents happen to the elderly and infirm while unattended at home (Living at Home, 2002). As robotic products emerge to ad- 
dress these safety problems, design research can support their broader usefulness and desirability to elders in their own environments.

\subsection{Ethnographic Studies of Aging}

The social sciences have a rich body of literature on aging and the elderly, much of it having implications for product design. Within sociology and anthropology, substantial ethnographies have examined the individual's experience of aging and interpreted that experience within social, cultural, and even economic frameworks (Bailey, 1986; Golant, 1984; Hazan, 1994; Silverman, 1987; Ward, La Gory, \& Sherman, 1988). These works provide valuable insight into understanding the role of objects, environments, and activities within the lives of elders and caregivers; they give designers clues for future product designs.

We found two of these studies to be of particular interest. The "Casser Maison" Ritual (Marcoux, 2001) provides a material culture perspective on aging. The author followed an elder who downsized her home and redistributed her possessions to others in preparation for moving to a care facility. In this situation, the elder retained products whose functions served her particular impairments as well as those that signified her former lifestyle. Dorfman (1994) described an "ideal" aging experience in an extensive ethnography of elders in a Quaker community. The context for the study, an upscale residential retirement facility, offered an environment Dorfman felt was void of many of the stresses common to elders. The values of remaining autonomous, sustaining personal growth, helping others, maintaining social ties, and experiencing pleasures were identified as important for this age group (Dorfman, 1994).

Our investigations identified a clear need for design research focused on how robotic products might support or hinder the values identified in this previous research; for example, keeping possessions that link one to the significant past. We focused our research on elders' relations with products they currently own. In an earlier study, we found that assistive products can feel threatening as well as helpful to people. One woman refused to install bathroom grab bars although her husband had fallen several times in the bathroom; the bars would have ruined the decor of the house (Hirsch et al., 2000). In a related study for a Pittsburgh company developing a wearable monitoring product to improve health and fitness practices, we asked men and women, ages 30 to 55 , to describe their reactions to a sleek, stylish, arm-worn medical monitoring device (McCormack \& Forlizzi, 2000). Despite the fashionable product form, over one half of the participants said they would not feel comfortable wearing it, particularly at work and in other public places. One third

of the participants described the product as reminding them of a lie detector or a blood sugar monitor, despite the high design of the product form. These pre- 
liminary studies suggested that we need a better understanding of how assistive products will be perceived and used.

\subsection{Ecology of Aging}

Our literature review and our previous research led to the development of a theoretical framework to guide our ethnographic research. An ecology is a set of interdependent parts that have particular relations within a system. Whether one is studying migration patterns in Liberia or the use of cleaning products in California homes, an ecological framework can be useful to examine relations among components of people's experience. In anthropology, cultural ecology is the study of the symbiotic relation between people and their social environment (Netting, 1986). Researchers using a cultural ecology approach collect detailed descriptions of people's behavior in their daily environments (Harris, 1979).

More recently, Nardi and O'Day (1999) used the term information ecology to describe an interrelated system of people, practices, values, and technologies within a local environment. An information ecology is used to situate new technologies ethically and responsibly, and to understand technology as a catalyst for change. Bell (2002) used the term ecology even more broadly, to include all the aspects of a specific experience in context. According to Bell (2001), cultural ecologies and the ethnographic research behind them help to

convey an experience, a sense, a glimpse, or a window into another world ... a way of talking about deep cultural patterns that implicate everything we do.

Knowing these stories, interests, and patterns makes it possible to design and

develop products and services that fit (intuitively) into people's lives. (p. 2)

Bell's (2001) approach seems most relevant for new product design because it offers a mechanism for examining multifaceted aspects of products.

We offer our ecological framework as a way to make sense of the experience of aging. It helps us to sift through the complex interactions between people, products, and activities, and the experiences that result. These interactions take place in a local environment bounded roughly by the home and the elder community. We have found it useful to consider these interconnected components of experience as an ecology of aging.

The components of the ecology of aging include people, products, the built environment, and the community. The components themselves can be systems or networks. For example, the elder's community is also a social network. Components may or may not reflect the roles and functionality they have in the rest of the society. The nurse's approach to providing care is drastically dif- 
ferent from that of the superintendent in an apartment building, but both may be called on to assist with a caregiving task.

The components of the ecology of aging are part of a system and are interconnected in the following ways: First, they are adaptive. If one part of the elder's life breaks down (e.g., an elder is no longer able to drive safely), another part must change (the elder will rely on family and make less frequent trips, or hire a community taxi service created specially for seniors). Second, the flow of information among components can be complex and can have unexpected consequences. An elder may rely on his or her primary care physician for information ranging from blood pressure to how to deal with depression. The physician, in turn, may rely on the elder's family for reports on the elder's general physical and mental well-being. The elder, in turn, may feel the family is interfering, and tell the family less. Third, the components are dynamic and evolving. An elder who has broken a hip will have a myriad of opportunities for assistance in the first few critical weeks, including family, institutional care, home health care, and private and government services. Choosing any one of these can cause the particular experience of an independent elder to change greatly. Finally, the ecology has the potential to break down. Continuing with the aforementioned example, if an elder's family imposes a move to a care institution, the outcome may be more detrimental than beneficial to the elder, resulting in reduced quality of life and well-being.

Our focus in this study was specifically on the role of products within the ecology of aging. Products play a role in a balanced ecology. They help well elders in a variety of activities and experiences, and support independence and well-being. For example, Mrs. G. disseminated information about social events at her community center, and made sure newcomers felt welcome by telling jokes and giving small gifts. Mrs. C. befriended her cleaning lady, preparing a home-cooked meal to share on housecleaning days. Figure 1a depicts an elder within a healthy ecology of family and social connections interacting with products and undertaking activities, connected and vital within a local environment.

The ecology of an elder experiencing decline can be described as one of imbalance. Changes in physical and cognitive abilities contribute to fundamental changes in product interactions. In turn, the elder is less able to undertake activities, and may relinquish independence and rely on assistance. For example, Mrs. R. was clearly struggling to manage her household, and was hurt and upset that her son had begun to "help" by removing items such as her prized Victorola. Mrs. L. relied on a local meal delivery service, but did not like the way the food was prepared and had begun to lose substantial weight.

Figure $1 \mathrm{~b}$ depicts the ecology of a declining elder who can no longer use all the products she formerly relied on. As a result, a gap is created between the elder and her environment, and a contraction of physical and social lifespace occurs. 
Figure 1. (a) A balanced elder ecology. Elders interact independently with products and people in their network of social connections. (b) An imbalanced elder ecology. Shifts in the ecology may be caused by the inability to independently and successfully use products, resulting in a gap between elder and environment. Elders need to rely on others for assistance and begin to contract services for household help. (c) An elder ecology sustained by future robotic products. Robotic products support multifaceted product interactions and activities. The elder has the same sphere of influence and quality of life as others in the ecology.

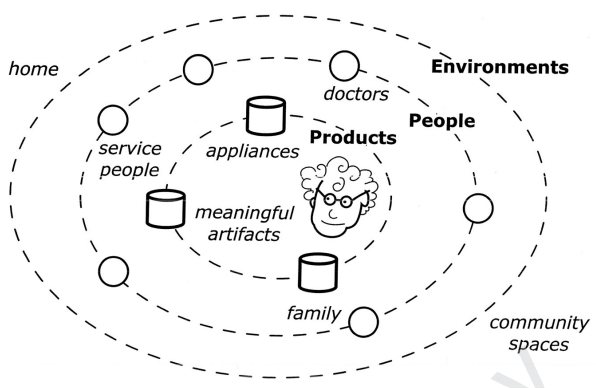

(a)

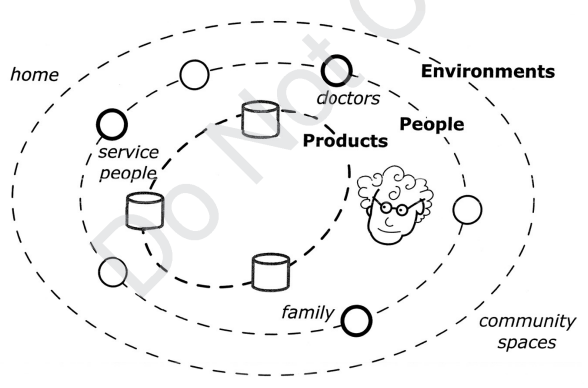

(b)

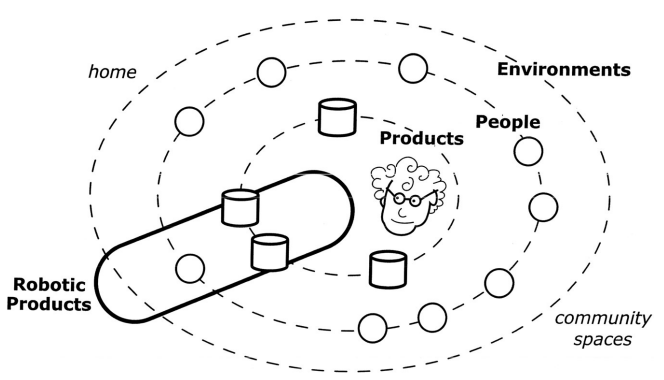

(c) 
Unfortunately, restoring balance to the ecology is often not an easy proposition. For example, an elder could experience rapid decline as the result of illness or an accident. A physician might believe that a safe solution is to place the elder in an assisted living facility. However, the elder might not want to move there, the family might not have the financial means to do so, or no space may be available in an appropriate facility. Alternative measures are often put in place - and a more suitable solution may never be realized.

We propose that assistive robotic products can address the inevitable change and instability of the elder ecology, and provide balance while allowing the elder to retain independence and dignity. Figure 1c shows how future robotic products might reinstate the balance within the ecology by mediating among components that are not realizing the elders' values and goals.

\section{METHOD}

Ethnographic design research methods have been adapted from anthropology (Geertz, 1973), other social sciences (Csikszentmihalyi \& Rochberg-Halton, 1981), and engineering (Button, 2000) to provide insights on how people form relations with products. Many of these studies have focused on how people create meaningful emotional relationships with products. Some have provided accounts of perceptions, attitudes, and beliefs about how products shape day-to-day activities. More focus on how people make sense of the formal and functional attributes of products is needed.

Design ethnographies focused on user-product interactions can contribute to the engineering and design of new products, artifacts, and services. Similar studies have provided ideas on how to bring technology to a traditionally technology-resistant user community (Salvador, Bell, \& Anderson, 1999). These issues are particularly relevant when dealing with new products, including robotic products.

In this study, we examined elders' activities and interactions with products, an area comparatively uncharted in the literature. We conducted qualitative semistructured interviews and observations with 17 elders living in 15 private residences in the Pittsburgh and Chicago metropolitan areas. We investigated typical daily experiences for these participants, and focused on how products support or hinder activities for this population. To give more context to our findings, we talked with five experienced visiting nurses and social workers in a home healthcare program sponsored by a Pittsburgh hospital.

We identified two types of individuals: well elders who were mobile, cognitively intact, and able to maintain their households with relatively little help; and declining elders, who were experiencing either reduced mobility, cognitive impairment, or problems performing household maintenance tasks (Figure 2). Well elders ranged in age from 68 to 79 . All 5 participants were 
Figure 2. Distribution of participants.

\begin{tabular}{lcccc}
\hline & $\begin{array}{c}\text { Live in } \\
\text { Family Home }\end{array}$ & $\begin{array}{c}\text { Live in a } \\
\text { Condominium }\end{array}$ & $\begin{array}{c}\text { Live in an } \\
\text { Elder-Specific } \\
\text { Community }\end{array}$ & $\begin{array}{c}\text { Live with } \\
\text { Adult Children }\end{array}$ \\
\hline Well elders & $n=2$ & $n=2$ & $n=1$ & - \\
Declining elders & $n=4$ & $n=2$ & $n=5$ & $n=1$ \\
\hline
\end{tabular}

women. In general, well elders spoke infrequently about the cognitive, physical, and emotional shortcomings associated with aging. Declining elders were older, ranging in age from 80 to 90 . Nine declining elders were women, and 3 were men; one of the interviews was conducted with a man and wife, and one was conducted with a brother and sister. Declining elders spoke frequently about how aspects of aging changed their day-to-day activities, and how products they used to rely on were no longer usable or accessible.

\subsection{Data Sources}

We recruited participants by posting signs in surrounding neighborhoods and through networks of neighborhood volunteers. One of our first participants recommended additional participants in more advanced stages of decline. Because members of our research team have lived in the cities in which we conducted this study, we had several opportunities to see our participants beyond the context of the interview, observing them anecdotally in other places.

We conducted an in-depth interview with each of the 17 elders to gain an understanding of their experience of aging. We focused on elders' individual and collaborative routines, changes in activities and product use, and attitudes and perceptions that emerge as aging takes place. All of the interviews took place in elders' homes. They were accompanied by home tours where elders described their homes; showed us their favorite products, most useful products; and products that caused problems or were seen as needing improvement. We also observed key household events for periods of about $1 \mathrm{hr}$-primarily meal creation, meal consumption, and grocery and item storage. Occasionally, the participant was prompted to speak about what he or she was doing. Sessions were videotaped and photographed. We collected data over a 4-month period, and we generated field notes after each interview. 


\subsection{Analysis}

Analysis of the data focused on creating participant profiles and reviewing and summarizing relations among participants, products, and the activities that specific products enabled or prevented. Products were coded using the Industrial Design Society of America (IDSA; 2002) standards for product categories. Activities were coded using the National Aging Information Center's (NAIC's) Activities of Daily Living and Independent Activities of Daily Living (NAIC, 1989), and the Extended Activities of Daily Living characterized by other research in the area of elder support (Mynatt et al., 2000; Figure 3).

\section{FINDINGS}

Our analysis of interviews with elders revealed the interconnected nature of their aging experience. Our ecological viewpoint proved to be useful in understanding a network of elders; the people they interact with; and their products, activities, and experiences all held in balance.

\subsection{People}

Our participants represent middle and upper middle class elders in America. They benefited from familial and financial support and had a variety of opportunities for social support and interaction through local senior centers and community groups. Our female participants also greatly outnumbered our male participants. Recent U.S. Census (2000) data revealed that women over age 65 compose $3 \%$ of the U.S. population, whereas men over age 65 account for only $2.6 \%$. Most of the elders and all of the caregivers we spoke to were women. This may motivate somewhat of a rethinking of what values we need to support with appropriate products and services for this group.

Within our participant pool, we noted differences in perceived status, or how elders in a particular community defined their position relative to others. Elders who had status-affirming experiences such as college educations; travel; and lucrative, fulfilling careers told many stories about their lives when they were younger. They also spoke of current social events, volunteer work, and proudly providing familial assistance to aging parents in the past and adult children in the present. Their current activities were carefully chosen to project values that were important at the peak of their adult life.

This behavior is often heightened when an elder moves to a new community and is afforded the opportunity to create new social relationships. For example, Mrs. C. is a 69-year-old woman who had divorced and moved 10 years ago to a modern loft-type condominium not specifically for elders. Most of her previous adult life was spent living in large traditional country homes, some 
Figure 3. Product and activity codes used in ethnographic analysis.

\begin{tabular}{lc}
\hline Products & Activities \\
\hline $\begin{array}{l}\text { P1 Assistive products } \\
\text { (hearing aids, walkers) }\end{array}$ & $\begin{array}{c}\text { A1 Activities of daily living (bathing, dressing, eating, } \\
\text { ambulation) }\end{array}$ \\
P2 Appliances and & A2 Instrumental activities of daily living (meal \\
housewares & preparation, household management, medicine \\
(coffeemaker, etc.) & management) \\
P3 Diagnostic equipment & A3 Extended activities of daily living (entertainment \\
(blood sugar monitor) & activities, social work, volunteer work) \\
P4 Entertainment products & A4 Communication activities \\
(stereo, television) & \\
P5 Medical equipment & \\
(medicine management) & \\
P6 Personal products and & \\
meaningful items & \\
P7 Services (cleaning, & \\
medicine management) & \\
P8 Technical products & \\
(computers, cell phones) & \\
P9 Transportation products & \\
(shuttle service, & \\
automobiles)
\end{tabular}

with more than 20 rooms. Describing this phase of her life, when she was working at a university and married to a successful businessman, she was proud of the quality of life she had and the ability to provide for others. She stated:

It was like I ran a boarding house in town for those years. My children had visitors, our family frequently visited, and we had a steady stream of businessmen and visitors from the university. How did I find time to work?

Her move into a condominium environment was both a reduction in space as well as a lifestyle change. However, it was important for her to continue to reference the status and activities from her former life. Describing her home, she continued:

It doesn't compare to any of my big old houses. But when my last child went off to college I thought, "What am I doing?" ... and I thought ... I'm just going to go someplace clean and modern. But all of my houses have been very old. So this is different for me. Most people have steel and leather furniture, and I just don't because it is not what I owned. 
Referencing her furniture and possessions, she alluded to her favored country overstuffed chairs and the fact that her condominium is twice as large as others, affording her space and a place for her adult son (R), who only occasionally spent the night: "... and R thinks of it as home, his bedroom and bathroom."

Mrs. C. also had a baby grand piano, a product that dominated over one half of her loft-style living room, although she could no longer play it due to chronic back problems. Through her discussion of the piano, we understood it to signify her previous lifestyle, although it was no longer usable.

Elders with fewer status-affirming experiences were often less interested in using status to define who they were in current communities. They sometimes avoided community events and social outings. Others framed recollections of family assistance as tasks they were expected to take on, infringing on personal rights and freedom. For example, Mrs. G. is a 79-year-old woman who is relatively healthy and socially engaged. During her interview, she described her younger years:

I didn't get an education, just high school. None of the girls in our family could get an education. We were all offered scholarships; we were all honors students and I couldn't get an education. My mother had three of us who were 18 months apart. The boys all got college educations. We went to work in the depression and supported them. I started to work at 14 and I got a good job during the war. I got a fantastic job with the government.

Signs of status were reinforced by how elders appeared during their interviews. Those of higher status showed and described clothing and jewelry collections, indicating that it was enjoyable to dress formally every day, wear makeup and jewelry, and have neatly coiffed hair. Interviews were generally conducted in the kitchen, and homemade food was offered. Those of lower status did not show clothing or the contents of closets during interviews. They wore loungewear or sweatsuits, occasionally had rumpled hair, and usually were not wearing jewelry.

We also found interesting patterns in our participants' patterns of product use that were indicative of activities and social interactions. For example, Mrs. A. had recently moved from upstate New York to live with her adult son in Pittsburgh. She purchased a cell phone to maintain ties with friends in her old neighborhood, but also to maintain her independence and identity within her son's home. Mrs. D. was mostly homebound and making do with her home appliances from nearly 50 years ago, but she had a new television and stereo. These had been selected and purchased for her by her children, in an attempt to improve her entertainment activities. Mrs. P. had a newly remodeled kitchen in her otherwise historic home. At first glance, it appeared to be mod- 
ern and aesthetically pleasing, but we found that the location of the oven, dishwasher, and refrigerator had been carefully planned for someone who had trouble bending and reaching. Mrs. P.'s close friend, a young architect, had helped her with the plan so that she could easily continue entertaining and socializing - activities she valued. These examples indicate that buying and using new products can be indicative of elders' values and the current state of their well-being in general.

These examples describe the elders we spent time with. They depict an aging culture that is particular to urban residential neighborhoods. Many of our participants lived in close proximity in apartment and condominium complexes that if not created specifically for elders, housed mainly senior citizens. Many of them knew each other because their children attended school together, or they were neighbors in former neighborhoods. We had the opportunity not only to observe them but to begin to understand the interconnectedness of their relationships in the elder community.

\subsection{Products}

How elders interact with products - whether they take the form of artifacts, services, or environments - plays a key role in defining the experience of aging. As elders begin to decline, why they want products, how they use products, and what they value about products changes. Elders are unique in their relationships with products for several reasons. First, elders generally have fewer reasons to make relations with new products as they age. Reduction in income, contraction in physical space, and reduction of social interaction limit opportunities to define relations with new products. Reduced or limited mobility also creates fewer opportunities for elders to interact with new products. Second, elders may adopt or ignore products based on how they reinforce personal identity and values, particularly during the transition to smaller homes and new communities. For example, housewares, art objects, furniture, clothes, and jewelry provide a clear message to the community about who an elder is and even the status enjoyed in adult life. Third, sometimes products designed specifically for elders (particularly assistive products) are stigmatizing and demeaning. These products are often not used at all or are modified to serve marginal uses. Product breakdowns like these create a gap between elder and environment, sometimes resulting in danger, isolation, and eventually institutionalization.

\section{Why Do Elders Want Products?}

We found that elders generally want products that match their aesthetic desires; that they use products that support their functional needs and abandon 
products that do not; and that the most important products are the ones that support elders' values of personal identity, dignity, and independence. After over a half century of interacting with products, many participants had adopted discriminating tastes. In our interviews, elders spoke at length about aesthetic qualities and personal meaning of cherished products. Products are traditionally used to define one's identity (possibly, in defeat of ageism), or to re-establish or maintain one's identity after relocating to a new home. For example, Mrs. A. is an 82-year-old artist who recently moved from her home in another state to live with one of her grown sons. The move forced Mrs. A. to reduce her possessions to those that were most important to her (her paintings and painting supplies) to fit in a home filled with her son's family's possessions. When comparing her current home to her previous home, Mrs. A. stated:

The transition here has been very hard. Breezy was my home. Here, I live here. I used to cook a great deal. I did my own laundry. Now, everything is different. It's hard. Although my days are active, I stopped driving when I came here. That takes your everything, your independence away. It's, well, as I say, hard.

Mrs. A.'s home tour focused on her artwork in every room, rather than any of the family photos or possessions on display. In our time spent in the dining room, where the family ate together every night, she talked only about her artwork:

That's one of mine. I would say that is something I did down at the beach. This is a view I would get from my house. I call it "Across the Bay." Why do you think I do short, wide paintings (laughs)? There's "Coney Island." There are a couple more paintings down here.

When she arrived at a shelf full of family photos and art objects, she chose only to describe a plaque that represented an art award that she had won. Through the objects that she chose to discuss during the interview, we felt that Mrs. A. was asserting her identity within her son's home.

Mrs. T. is 81-year-old woman who has lived in an elder high rise for 7 years. In the last 2 years, she had begun to decline rapidly, causing her son to become more concerned and to increase the amount of support and interaction he provided. During her interview, Mrs. T. spoke at length about an air conditioning unit purchased by her son:

My son came in from Arizona, and he said "Mother, how could you live in here? It's so hot!" and he went to Home Depot and he bought it and he put in himself. I don't like the looks of the window, you know, 
[referencing the connection to the window done in a crude manner with a large plastic hose] but ... it is pretty [referencing the unit]. $\mathrm{He}$ paid over six hundred dollars for it ... and then he needed another part, so he went out, back to Home Depot and bought another part. And you take it out in the wintertime. The janitor and the maintenance man will take it out in the wintertime when it gets cold. I'll have them put it back in and maybe they will do it right. But my son was in a hurry and he wanted to make sure that he got it for me.

Rather than describing its function, Mrs. T. chose to discuss the fine quality of the air conditioner, even describing it as pretty. We interpreted this exchange as being indicative of her pleasure in having her son contribute to a comfortable living environment.

\section{How Do Elders Use Products?}

Elders use products because the functional aspects of products meet their current needs. Products are instrumental in completing a variety of daily activities. This reason differs from that of the young population, who often uses products because of stylistic considerations regardless of functionality. The elders in our interviews told many stories of how household appliances; transportation products; and communication products such as telephones, cell phones, and computers enabled them to help themselves, provide for family members and friends, and stay in touch with people in their social network.

Mrs. N. is an 80-year-old woman actively engaged in her community. She expressed pride in being able to help an acquaintance $(\mathrm{P})$ in need, despite her own recent recovery from a bout of pneumonia:

Even though I am on hiatus [from many of her usual activities, due to pneumonia], once a week, I take P shopping. She is a person in the building. That's my helping work. Every Friday we go have our hair done, then we have lunch, then we do the shopping.

Whereas well elders mentioned product successes more frequently than product failures, declining elders talked at length about how the functional aspects of products and environments no longer served them. Eight of the 12 declining elders that we interviewed discussed how they could no longer easily make use of bathroom tubs, toilets, and fixtures; kitchen appliances, tables, and counters; telephones; clock radios; grocery carts; automobiles; and public transportation to support their basic needs.

Mrs. L. is a 79-year-old woman who suffers from depression, insomnia, neural degeneration, gastric reflux, and balance problems. She lived in a 
high-rise condominium for elders, but the design of her bathroom made it so inaccessible that she had great difficulty using it (Figure 4a). This was especially evident as she described the bathtub, shower, and hot and cold water faucets relative to the shortcomings of her own body. In describing the process of taking a shower, Mrs. L. commented:

This apartment was made for old people, and they knew it when they made it. Yet why would they put that up so high? [referencing the height of the shower rod] I can just barely hang anything over there ... it really is much too high. And another thing, I'm not so smart my dear, this faucet, I mean, you have to be a rocket scientist to use this faucet! I think it's very hard to use. Until I get it running right, I am ready to give up on it.

Unfortunately, environmental shortcomings such as the ones Mrs. L. described in the bathroom are enough to force elders to reduce their standards of personal hygiene.

Six of our participants showed and described modifications they had made to communications products and housewares, to increase accessibility. Our male participants described the process of modifying a product as an exciting challenge, whereas our female participants described it in terms of pure need. Modification results in a personalized product that is satisfying to use, as a conversation with Mr. G. about his personalized desk illustrates (Figure $4 \mathrm{~b}$ ):

Yes, yes, I fixed that thing [the desk] up for myself. I did that for myself. It holds my envelopes, papers, pencils ... everything is in there. I work on it periodically. If I see a box that looks better, I might take one down and put a new one up there instead.

As elders' bodies continue to decline, problems with products continue to be magnified; are less likely to be corrected; and ultimately result in messy, unsafe environments with more than one product to serve the same function. For example, Mrs. V. is an 81-year-old woman struggling with basic activities of daily living. During her interview, we noticed two radios on her bedside table, and we asked why (Figure 5a):

You know what, [pointing to digital clock] I never used that as an alarm. I don't know how to set it. I use this one [pointing to analog clock] — but it is not any good ... I have to get a new one. I use this one [pointing to digital clock] to look at the time. 
Figure 4. (a) Mrs. L.'s water control in her shower was hard to understand and use and resulted in her bathing less frequently. (b) Mr. G. took great satisfaction in modifying his desk.

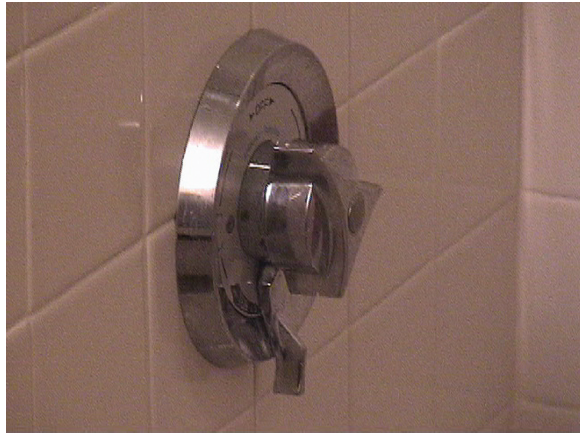

(a)

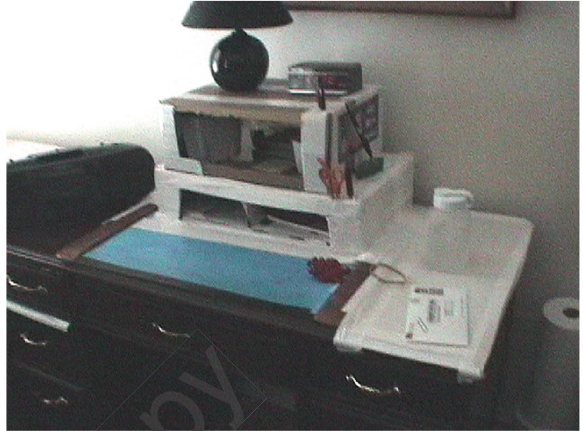

(b)

Figure 5. (a) A clock radio no longer serves someone with vision and muscular limitations, resulting in use of more than one product. (b) Bending and stretching to reach storage areas becomes difficult, resulting in using the counter for storage and disarray in the kitchen.

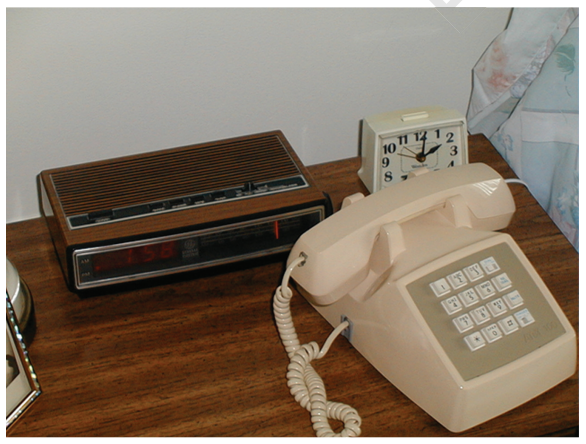

(a)

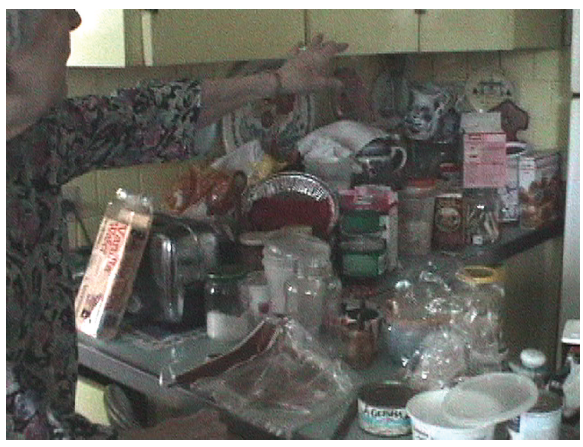

(b) 
The shortcomings of kitchen environments can make normal meal preparation difficult and even dangerous for elders. Mrs. G. kept busy baking a quiche and preparing fruit salad while we interviewed her. At one point, she needed to retrieve a container from a cupboard over the stove that was out of her reach. To do so, she took a broom and repeatedly jabbed it into the open cabinet until the item that she wanted fell out and on the floor. During this process, several other items fell out of the cabinet and landed on the stove, presenting a fire hazard. Mrs. G. also had trouble reaching items in the refrigerator, which was filled with containers of food in precarious locations and in various stages of deterioration.

Mrs. R. is a 90-year-old woman who is losing control over maintaining her home of 43 years. Her kitchen was also in a dangerous state of disarray (Figure $5 \mathrm{~b})$, which she repeatedly blamed on her laziness:

My kitchen isn't fit to be seen ... . [Mrs. R. starts cleaning passively, and interviewer tells her it is unnecessary] Well, I'll get around to it. It's not bad looking when you take all the stuff away. I'm just too lazy to do stuff ... It's not bad when you can see all these plates, if I take time to clean. But I'm just maybe lazy or ... (she trails off). [Interviewer asks if Mrs. R. uses the cupboards at all for storage anymore] Oh yeah, I've got my dishes. [Opens cupboard to reveal dishes and glassware wrapped in newsprint and plastic bags] And I use all this stuff in here. Well, if you look in here it's a mess. My son is after me, he says, "Do you want all that stuff on the floor? Put it in the basement or lift it up."

If elders can understand how assistive products can help them remain independent, they are likely to consider and accept using products such as hearing aids, dentures, canes, walkers, and wheelchairs. Without this understanding, there is resistance in acquiring and using assistive devices. We heard misconceptions about what assistive products are appropriate, and how they might be acquired. Out of the 12 declining elders that we interviewed, almost three fourths were not able to recognize the need for assistive products, and nearly one half had severe misconceptions about their purchase and use.

For example, through a conversation with Mrs. G., we interpreted that she was in denial about her failing health and ambulatory abilities. Although her doctor recommended surgery, she chose to avoid it for as long as possible:

I said, "Well I'm not doing it!" [referencing her doctor's request that she have knee surgery]. I'm going to fight it-I'm going to work it out. I do it myself, I found out that if I use the topical medications ... I can do it with exercising. I'm doing fine. Anyway, the doctor said I have to 
have it done [the surgery] so I said that I'm up in years now, would it make any difference when I have it done? I'm going to be eighty, so therefore is it bad? He says it doesn't make any difference. Now I'm really actually not going to have it done unless I have to. I'm going to wait until I can't walk, if I can pull it off, and I don't know if I can pull it off. That's the unknown.

Mrs. V. had accepted her decline, but seemed wary of assistive devices and unwilling to think about making changes to her home. An 80-year-old declining elder, she had suffered cancer and serious infections related to surgery a few years ago and had used a walker during her long convalescence. When asked about using her walker, she commented:

Well, I must have used it that whole month. I couldn't walk [while recovering at home from cancer], and I did not want a wheelchair. The reason I did not want a wheelchair-I would become an invalid! It's so easy to become an invalid. See you don't realize it when you are young .... .

This exchange suggests that although Mrs. V. was aware of her current need for assistance, she feared that by responding to it she would only decline more quickly. During her interview, we observed Mrs. V. having trouble with many of the products and environments within her home. She had ceased using many products altogether. Although simple modifications could have been made to drastically improve her quality of life (e.g., by asking her children or a cleaning service to help remove clutter and unused products), she seemed to be unaware of the benefits. When asked what changes she expected to make in her home in the next 5 years, she responded that if her husband would let her, she would like to build a patio off of the kitchen. Her inability to perceive the need for change not only presented an immediate physical hazard but also increased the likelihood that Mrs. V. would need to leave home for a professional care community.

Elders who accept physical and cognitive decline seem to be more willing to explore the use of appropriate assistive products. However, they often lack appropriate information to make decisions about what products will be the right ones. Mr. and Mrs. H. were aware of the shortcomings of old age and had begun to modify their living space by having custom cabinets built; placing an amplifier on the phone; and using specialized tools, such as electric can openers, in the kitchen. However, they told an interesting story about grab bars installed by the previous resident of their apartment: 
When we moved into this place, these rails, well she [Mrs. H.] said, "they have got to go." It wasn't too long before we realized they are really useful, particularly for getting up from the john and the tub. [Interviewer asks why they wanted to remove the grab bars] Well, we didn't think we needed them. We were a young couple ten years ago! We were only in our 70s. Who needed them? The old lady who used to live here, her doctor son had them installed. It wasn't very long before we realized, it was a blessing to have them. Well [Mrs. H.] is pretty husky, and it is difficult, and she has trouble breathing. She has to use all her energy for breathing.

Despite the fact that Mr. and Mrs. H. had made many modifications to their home, it was only through direct experience of the grab bars that they realized their utility.

As elders continue to decline, they must begin to rely on family, friends, neighbors, or acquaintances to perform basic household tasks. Direct experiences with assistive products, such as the one described earlier, may be useful in illustrating the utility of assistive products and services. Fear and trepidation often accompany making the choice to try a new product or service, partly because of the fear of the unknown and partly because accepting these products and services is often seen as stigmatizing or as a sign of admitting defeat.

We have seen that elders choose products that please them aesthetically, products that will support them functionally, and products that are indicative of personal identity. In the next section, we explain how products support values important to those we interviewed.

\section{How Do Products Support Values for the Elder Population?}

Our explorations of elder experiences revealed that independence and dignity were unanimously important to this population (see Dorfman, 1994). These values have behavioral and emotional aspects. Behavioral values are acted out in interactions with products and self-held standards for conduct and appearance-for example, being nicely dressed when interviewers arrived and offering home-cooked food as if we were guests. Emotional values are surrounded by intense feelings, and are often acted out in defensive arguments about particular behavior. Independence and dignity were evident in elders' stories about both products and activities. For example, Mrs. L. insisted on driving to do errands, although it was unsafe, rather than relying on her daughter, with whom she had a distant relationship. We interpreted this behavior as her way of asserting her independence from her daughter.

Independence, the state of being competent and self-supporting, is a common value for many adults, regardless of age or lifestage. For example, consider the 
independence cherished by a 16-year-old girl who has just learned how to drive and is experiencing the first of many interactions with a vehicle. For elders, a shifting of capabilities causes a particular reprioritization of products and activities that help them assert their independence. For example, many of our participants used cell phones to maintain social connections even as they had to rely on others to drive them to social functions. Independence was manifested behaviorally through product choices like these, and in actions like choosing to drive or to stay in a large home. Independence was manifested emotionally in the stories we elicited about how elders envisioned their future lives. A common response often began with, "My children have offered to help, but my hope is not to burden them."

Dignity, the state of being worthy of respect, is a particularly important value for elders. In our interviews, dignity was behaviorally manifested in an elder's desire to maintain a particular personal standard within the home or the community. For example, 9 of our participants had hired cleaning services to assist with household management. At least 3 of these elders had forged close friendships with the women who cleaned their homes. We interpreted these friendships as being indicative of managing the admission that help is needed at home with dignity.

Mrs. K. had a Hemlock Society publication hidden among her pile of magazines. Explicitly removing it from the stack and revealing it to us, she explained:

I belong to this [the Hemlock Society]. Instead of being left to die in agony, I would rather go when I am still ... able. I did not tell my family.

My son would have a fit if he knew.

Rather than relying on her family to decide what to do when she experienced significant decline, Mrs. K. instead preferred freedom in making choices about the end of her life. We interpreted this as her way of asserting both her independence and her dignity over making final choices.

The exploration of these values and how they are manifested through interactions with products reveals how our participants prioritized products and activities that supported independence and dignity. Personal standards for products changed when the elder ecology shifted.

\subsection{Environments}

Environmental reduction is a critical component of the experience of aging and plays a role in the elder ecology. The environmental press theory has shown that reduction in environmental and social opportunities plays a significant role in the aging experience (Lawton, 1982). The home becomes especially 
important as time spent in travel, work settings, and other spaces declines. As elders move to smaller homes, they seek desirable surroundings in new and smaller spaces (Ward, La Gory, \& Sherman, 1988). We observed three types of home environments. The first type was a participant's original home, inhabited for more than 15 or 20 years and occupied when the participant was younger and not subject to the shortcomings of old age. These were often expansive homes, filled with a collection of products and artifacts, showing few signs of change or modification. Often, several rooms within these homes were no longer used, or were used for the storage of random items. The second type was a small home, condominium, or apartment not specifically in an elder high rise. These spaces often showed signs of contraction and were inhabited as the result of a significant life event, such as divorce or the death of a spouse or child. The third type was an apartment or condominium in an elder community. These spaces were generally designed to support physical decline. Many of them had been further modified by our participants. Elder communities often had public laundry facilities and service staff, such as superintendents, to help residents. They also had community spaces where formal and informal social gatherings took place.

Many of the environments we saw in our interviews (even those designed and constructed specifically with elders in mind) did not fully accommodate participants' needs. Bathrooms and kitchens had particular shortcomings that impeded activities of daily living. Water controls are notoriously poorly designed (Norman, 1990). The problem was exacerbated for our population, as witnessed in our interview with Mrs. L. Her solution was to take fewer showers.

Kitchen environments often fail ergonomically. As elders decline, they may have limited physical mobility, which makes reaching kitchen surfaces, storage areas, and products situated within the kitchen quite difficult. In several kitchens (such as Mrs. R.'s discussed earlier), we found collections of foods, appliances, and other kitchen products in disarray on the kitchen counters.

In general, storage was a problem for most of our participants. Many could not see, let alone reach, upper and lower shelves of kitchen cabinets and storage closets. Only 3 participants had been proactive in reconciling this problem. One couple had custom cabinets built, and another participant had her cupboards rehung 8 in. lower so she could reach the shelves. Mrs. L.'s son built new shelves in her hall closet, creating an accessible space that she could use for customizable storage of toiletries and medications.

Usability and accessibility of the kitchen can make the act of preparing and eating food unsafe, tedious, and no longer enjoyable. We witnessed Mrs. L. making lunch in her kitchen. Her degenerative muscle disease made it very difficult for her to stand at the counter and use a paring knife to make a sandwich. Mrs. L. also had trouble getting in and out of a chair, so she had to continue to stand uncomfortably at the counter to eat lunch. 
We used participants' comments about environmental shortcomings in bathrooms and kitchens to prompt a discussion of their perceived need for changes to home environments in the next 5 years. Not surprisingly, our participants were hesitant to describe changes in the foreseeable future. The majority of those we interviewed were clearly in the process of understanding and accepting various stages of decline. Most reported little need to make changes and instead described changes to the home in terms of aesthetic remodeling.

\subsection{Activities and Experiences}

We found that elders' interactions with products facilitated activities, mediated social interactions, and evoked experiences that contributed to their sense of self. Properly designed products and assistive products played a key role in helping elders undertake activities. Activities that promoted social interaction were extremely important for this group. They played a critical role in helping elders to remain healthy, happy, and independent. Our participants cited a large range of activities that helped them stay engaged socially. The inability to participate in these activities resulted in contraction of their social space.

Our participants undertook a variety of activities, including family outings, visits to friends' homes, meals, volunteer activities, and religious and community events. Many activities mentioned were not explicitly described as social, but were implicitly social in nature. These included lifelong learning classes, exercise classes, doctor visits, and assistance to neighbors in the community.

We believe that particular living arrangements supported frequent social interactions with both family members and the community. Mrs. G. said she "maintained" two households-one with her estranged husband and another with her daughter and granddaughter. Mrs. G. spent most of her time at her daughter's house, providing "assistance" in buying food and preparing meals. We observed her working in her kitchen during our visit. The kitchen cupboards and the refrigerator were in a state of general disarray. Several times while cooking, Mrs. G. neglected to clean the utensils before placing them back in the drawers. These observations suggest that the relationship was more a social than a practical necessity for Mrs. G.'s daughter and granddaughter. Mrs. G. may have been acting beyond her capabilities and possibly straining the very relationship she believed to be helping.

Volunteering and helping others are activities that strongly define an elder's sense of self-identity. For example, Mrs. C. participated in four different volunteer activities. She was a founding member of a cooperatively managed used bookstore, a church trustee, a trustee at a credit foundation, and a board

member for a local school organization. In addition to participating in these activities, she helped others to participate by driving to and from events. 
We saw that decline, mediated by breakdowns in product use, drastically reduced elders' activities. At that point, many activities not ostensibly intended for social interaction in middle age became valued points of engagement in old age. These included activities such as doing laundry in a communal facility, receiving a visit from a home nurse, or participating in exercise and physical therapy classes. Nine of the 17 elders that we interviewed participated in at least one such activity every week, if not every day. These activities were described in social rather than functional terms. They often provided an opportunity to leave the house, meet peers, and make light of aches and pains. Many physical therapy and exercise classes took place at senior community centers rather than hospitals, further emphasizing their social nature. Often, exercise made our participants feel young and desirable. Mr. H., who exercised nine times a week, proudly professed, "I'm a jock, and I get to spend lots of time with widows!"

Gradual, yet substantial, decline in abilities can have especially damaging effects on social interaction, because elders can simply give up. Figure 6 compares the number of times activities of daily living, instrumental activities of daily living, extended activities of daily living, and communication activities were mentioned during interviews. Declining elders mentioned basic and instrumental daily activities more frequently, consistently describing disappointment in no longer being able to successfully undertake a given activity.

Mrs. L. was a poignant example of this disappointment. Her physical decline was recent, but rapid and extensive. At the beginning of the interview, Mrs. L. commented:

Everything has changed. I mean, my life is completely different [since the onset of multiple conditions]. But I still try to go and do. My neighbor has asked me to go to lunch. I see her, and she says, "When are we going?" I hate to have to tell her that it is just too hard.

Mrs. L.'s situation is interesting to interpret. Over the course of the interview we began to understand how difficult social interaction had become for her. She occasionally drove to the grocery store and the beauty salon, went on outings with her family, and maintained relationships with a few women in her building. However, she spent most of her day watching TV, despite the fact that her friends made repeated efforts to engage her socially. Near the end of the interview, she commented that socializing was becoming too much of an effort. We felt this indicated that Mrs. L. still desired social interaction but that the shifts in her ecology were making social engagements harder and harder for her to undertake. These kinds of situations can lead to isolation or even danger. Mrs. L. could eventually give up attempting social engagements, although they may be quite feasible with proper assistance. 
Figure 6. Frequency that well and declining elders mentioned different activities.

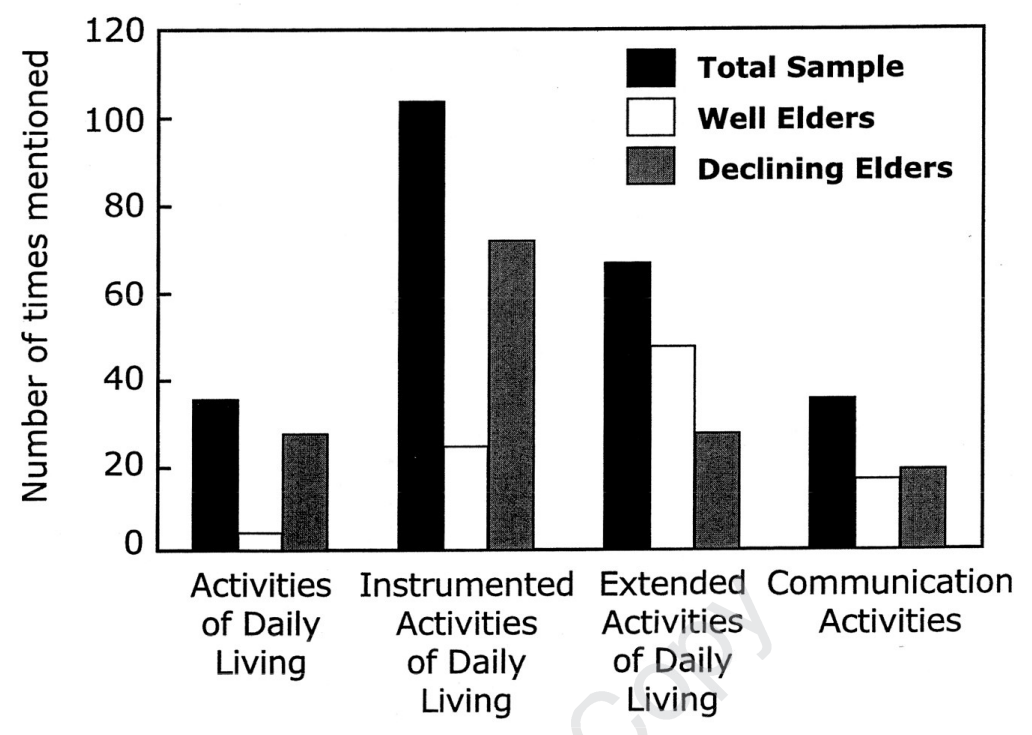

Although assistive products are often described as facilitating the activities of daily living by making those activities accessible to people with physical or cognitive disabilities (Fernie, 1991), our interviews showed that assistive products could also play a powerful role in helping elders to create socially engaging experiences. Mrs. T., an 82-year-old woman suffering from degenerative muscular disease, provided a clear example of how an assistive product can serve social needs. Mrs. T. could barely swallow, walk, or get in and out of a chair, and she fell several times a day. Despite of all this, she insisted on taking part in the informal social gathering each afternoon in the courtyard of her building. In the past year, it was only after acquiring a walker that she could even attempt this activity. Although she relied on others for almost all aspects of personal and household management, she enjoyed having the agency to partake in this social activity. We believed that her walker was valued not in terms of facilitating her mobility but instead in terms of creating opportunities for her to socially engage with the world.

\subsection{Summary of Findings}

Within the framework of the ecology of aging, we found that for elders, products can meet (or be adapted to) newfound needs, but especially when el- 
ders decline, they can serve as a source of frustration and hardship. For example, a walker represents the chance to maintain one's autonomy, but if it is heavy, ugly, and cannot be used outside, its acquisition can instead prompt greater reliance on others or, if getting help is impossible or undesirable, isolation. This example reflects our major finding that many products used in and around the home can represent values for elders that they do not represent for those at younger ages and that products can have some unintended consequences for elders as well. For example, the cell phone begins to substitute for the car as a way to contact others. We believe our results point to considerations for ecologically sensitive design of robotic assistive products.

Our study has several limitations such that further observations are warranted. In particular, our study used a small sample. Also, it was geographically bounded by two Midwestern cities and physically bounded by our participants' homes. Increasing the diversity of participants could improve our understanding of how to design products for a broad population. For instance, one of our participants, a retired engineer who designed his own sleep apnea device, will most likely react differently to a robotic product than a female participant who never learned how to drive. Robotic products may need to have familiar appliance-type product forms that are generally acceptable to a variety of users, or robotic technology may be added to familiar and widely used products and environments. Increasing sample size and diversity will also increase the diversity of observed environments. Each home has idiosyncrasies that differentiate it from other homes as well as from institutionalized settings (Michelson \& Tepperman, 2003). Finally, longitudinal studies of the transition from homes to institutions could provide more clues about how elders' lives unfold.

\section{ROBOTIC PRODUCTS TO SUPPORT THE ECOLOGY OF AGING}

Robotic technologies have now reached a level of sophistication that makes deployment in the home feasible. Conceiving of the aging experience as a set of interrelated independencies within an ecological system is a critical first step for designing robotic products suitable for elders. Our ecological framework exposes the many important contingencies that exist in designing products to provide a good quality of life for elders and those who provide care for them.

Later, we use our data to suggest guidelines for the design of appropriate robotic products for elders in their homes. Our guidelines are necessarily broad and preliminary. Technology development is rapid. Our description of the experience of aging is not frozen in time. The experience of aging, and technologies, will certainly change in the next decade. Although we can describe the changes and dependencies we witnessed in the ecology of today's elders, we 
cannot confidently project those needs 5 to 10 years into the future. We believe, however, that our design guidelines can serve as initial "rules of thumb" for addressing design goals for robotic product development for elders in the home.

In the future, robotic product design might become as common as consumer product design. As we learn more about this new area of product development, we will generate more specific principles and begin to populate the landscape with detailed case studies of robotic products that chart the course for future research and design.

Our research, and that of those in the technical research community (Kawamura, Pack, Bishay, \& Iskarous, 1996; Schraft, Schaeffer, \& May, 1998), has begun to identify specific needs and values future robotic technologies might support for this population. Some of these include support in managing the home; maintaining personal and household supply; monitoring and providing ambulatory support; and most important, providing communication and social interaction. Our ethnography revealed needs ranging from making meals to having mail read. Although these are good starting points for generating product ideas, we also advocate taking a holistic approach and thinking about how future robotic technology might impact the elder ecology as a whole. A robotic product has the potential to be a powerful technology-engaging with it will have different, unexpected, and potentially negative results. The following guidelines begin to chart a course for successfully integrating new products into the lives of elders.

\subsection{Design Guidelines}

\section{Robotic Products Must Fit the Ecology as Part of a System}

Robotic products designed for an elder ecology must be conceived of as part of a larger system of existing products and environments that serve elders and others in the ecology. When designing, first-order effects (such as fit) and second-order effects (such as social and cultural implications) must be considered. Familiar product forms with augmented product functionality will fit the system and maximize early product adoption.

As part of a larger system, future robotic products need to offer diverse interactions to many different groups of people. One of the most formidable tasks for designers is to conceive of and construct the interactions that will take place between elders, future robotic products, and others in the elder ecology. We will not be able to predict how the social situations and surrounding physical context will respond to, and create unanticipated uses of, future robotic products within an elder ecology. For example, an elder might use a robotic product to communicate with her daughter, primary physician, physical ther- 
apist, and even pharmacist. Rather than a product that is used by one person, such a product offers opportunities for interaction among all members of the elder ecology. These products should maximize fit by allowing the elder to experience the same power, control, and agency as others in the elder ecology.

Part of the designer's task is to understand how these products situate within the ecology and what kinds of second-order effects will occur. For example, refrigerators were designed to keep things cool, but have also informally become a vertical communication space through the use of refrigerator magnets for notes, artwork, cartoons, and family communications. Similarly, we observed a robot designed to deliver medicines in a hospital. The robot was repeatedly decorated with flowers and stickers by hospital patients as it made its rounds. In thinking about product function and aesthetics, it will be important to consider what intended and unintended opportunities for communication, sharing, and new experiences future robotic products will offer.

\section{Robotic Products Must Support the Changing Values of Those Within the Ecology}

Robotic products designed for an elder ecology should uphold the important values of independence and dignity. They should also allow for different prioritization of these values. When designing product functionality, allow for basic needs as well as higher needs to be addressed. Combining appropriate and accessible functionality along with aesthetic considerations will support values and sustain product use.

Our description of the experience of aging has shown that change is inevitable for elders - change in their physical and mental abilities, and change in the local environment in which they live. These changes account for endless shifts in values, individual prioritizations of values, and endless differences in the elders we interviewed. Robotic products need to support these shifts in values by responding to different decisions and actions in any given situation.

Interactions with these products should not detract from the elder's independence and dignity. They should allow elders to do as much as possible, by enabling people, instead of the system, to initiate most of the interactions with the product. To help the elder feel comfortable using new technologies, future robotic products should allow for flexible and accessible use. All interactions should be designed to support use and maintain the values of the widest variety of people. The Universal Design Principles (2002) developed in the last decade have ensured that product functionality serves the widest group of human needs. It is essential that products also serve the widest group of human values by supporting the many forms of independence and agency within the ecology. 
Future robotic products should also support independence and dignity by maintaining the best quality of life that the elder has known, or perhaps, improving it significantly. In evaluating future robotic products and their effect on the elders who use them, we will need to move beyond cognitive and ergonomic issues and deeply consider the human-machine relation, focusing on the network of relations, values, and motivations involved in an ecological view of adopting new robotic products.

\section{Robotic Products Must Be Functionally Adaptive}

Robotic products designed for an elder ecology must be adaptive. They should provide a solution for today as well as solutions that will support future change. When designing products, allow for extensible and mutable forms and functions.

Robotic products that are situated successfully within an ecology will support change and growth, fostering new activities for everyone to be involved in, as well as conditions for adaptation; new knowledge generation; and creative problem solving rather than accepting less than desirable situations. One pertinent example from our earlier research in a nursing home can provide some insight. The community received two desktop computers with Internet access, and placed them in a public room on the first floor of the building. Although the staff at first believed that there would be little uptake of this new technology, they quickly learned that just the opposite was true. A few knowledgeable staff and residents were quickly elevated to the level of "local experts," and signup sheets had to be created to regulate fair use of the equipment. Residents asked for lessons on how to use the computer, and eventually, a technical staff member was hired. One year later, the presence of the computers had facilitated new social interactions. Residents had taken over the production of the community newsletter, and other project plans were underway. As a result of the new technology, all of the components of the ecology were evolving. In addition, the technology was evolved by the technical staff member to make sure it continued to serve the ecology.

These design guidelines can be generally applied to the design of assistive robotic products. Specific design solutions will bring more knowledge to this new area of product development. Figure 7, for example, shows how our generative findings can lead to more specific design recommendations. As more specific principles are discovered, more detailed case studies will follow.

\subsection{An Ecological Approach to the Design Process}

Design is the human activity of conceiving, planning, and making the artifacts, services, and environments that contribute to the best quality of human 
Figure 7. Summary of preliminary design guidelines and example design recommendations.

\begin{tabular}{ll}
\hline Design Guideline & Example Design Recommendation \\
\hline $\begin{array}{l}\text { Robotic products must fit the ecology } \\
\text { as part of a system. }\end{array}$ & Consider scale and footprint \\
& Consider placement in the home \\
environment & Make the product portable and usable \\
beyond home context \\
Use familiar product forms to inspire \\
early adoption \\
Provide a natural, "walk up and use" \\
interface \\
Allow the user to initiate product \\
interactions \\
Provide more than one choice to \\
migrating values of elders and others \\
complete any given task \\
Provide options for aesthetic appearance \\
Provide multimodal input and consistent \\
lightweight output \\
Robotic products must be functionally \\
adaptive. \\
the largest number of people in the \\
ecology \\
Provide mutable functionality for \\
different users and contexts
\end{tabular}

life. The activity of designing is common to a number of disciplines: engineering, science, art, rhetoric, and others. However, there are fundamental differences between how designers approach design (searching for solutions to witnessed problems) and how those in the harder sciences approach design (engineering new technologies in usable forms). The ecological framework presented here can provide a checks-and-balances system for all of the disciplines involved in the act of designing.

When designing new robotic products, we will need to make judgments about what technologies to pursue, what systems to make, and how to consider context when designing artifacts and services. Design problems of this kind are characterized as "wicked problems"; a class of social system problems that are ill formulated, confusing, and influenced by many decision makers. Wicked problems are indeterminate, meaning that there are no definitive solutions and more than one appropriate solution to any given problem $(\mathrm{Bu}-$ chanan, 1995). 
Our ecology of aging brings a human-centered focus to designing future robotic products for the aging population. It bridges the gap between the many disciplines involved in the act of design. It allows for a number of solutions to address the needs and values associated with aging in place, by providing an approach for indeterminate and multidimensional problems. The ecology of aging allows us to formulate and test solutions while continually deepening our definition of the design problem. It allows us to take a checks-and-balances approach to design the best solution for all the components of the ecology-people, products, and activities taking place in particular environments. The ecology shows that technology is not the only influence in designing new products-social dynamics, economics, and environmental issues also play an important role.

\section{NOTES}

Acknowledgments. We thank John Zimmerman, Michael Gillinov, and our anonymous reviewers for their helpful comments on the article. We thank Ann Kauth for her assistance with data collection.

Support. This research was supported by a grant from the National Science Foundation grant IIS-0121426.

Authors' Present Addresses. Jodi Forlizzi, Human-Computer Interaction Institute, Carnegie Mellon University, Pittsburgh, PA 15213. E-mail: forlizzi@cs.cmu.edu. Carl DiSalvo, School of Design, Carnegie Mellon University, Pittsburgh, PA 15213. E-mail: disalvo@andrew.cmu.edu. Francine Gemperle, Institute for Complex Engineered Systems, Carnegie Mellon University, Pittsburgh, PA 15213. E-mail: gemperle@cmu.edu.

HCI Editorial Record. First manuscript received December 2, 2002. Revision received June 2, 2003. Accepted by Sara Kiesler and Pamela Hinds. Final manuscript received September 16, 2003. - Editor

\section{REFERENCES}

Bailey, M. (1986). Golden years, tarnished hours: Ethnography of two elderly residences in the Midwest. Unpublished doctoral dissertation, University of Michigan.

Bell, G. (2001). Looking across the Atlantic: Using ethnographic methods to make sense of Europe. Intel Technology Journal, Q3, 1-10.

Bell, G. (2002). Making sense of museums (Technical Report). Portland, OR: Intel Labs.

Buchanan, R. (1995). Wicked problems in design thinking. In R. Buchanan \& V. Margolin (Eds.), The idea of design (pp. 3-20). Cambridge, MA: MIT Press.

Button, G. (2000). The ethnographic tradition and design. Design Studies, 21(4), 319-332.

Computing Research Association. (2003). Grand research challenges in information systems. Washington, DC: CRA Press. 
Csikszentmihalyi, M., \& Rochberg-Halton, M. (1981). The meaning of things. Boston, MA: Cambridge University Press.

Dorfman, K. A. (1994). Aging into the 21st century: The exploration of aspirations and values. New York: Brunner/Mazel Inc.

Dubowsky, S., Genot, F., Godding, H., Kozono, A., Skwerrsky, H., Yu, H., et al. (2000). PAMM - A robotic aid to the elderly for mobility assistance and monitoring. Proceedings of the IEEE International Conference on Robotics and Automation. New York: IEEE.

Fernie, G. (1991). Assistive devices, robotics, and quality of life in the frail elderly. In J. E. Birren, J. E. Lubben, J. C. Rowe, \& D. E. Detuchman (Eds.), The concept and measurement of quality oflife in the frail elderly (pp. 142-167). New York: Academic.

Geertz, C. (1973). The interpretation of cultures. Chicago, IL: Basic Books.

Golant, S. M. (1984). A place to grow old: The meaning of environment in old age. New York: Columbia University Press.

GuideCane. (2002). The Guide Cane. Retrieved December 1, 2002, from http:// www-personal.engin.umich.edu/ johannb/GC_News/GC_News. html

GUIDO. (2002). Guidosmart Walker. Retrieved December 1, 2002, from http:// www.haptica.com/id2.htm

Guralnick, J., LaCroix, A., Abbott, R., Berkman, L., Satterfield, S., Evans, D., et al. (1993). Maintaining mobility in late life. American Journal of Epidemiology, 137, 845-857.

Haptica. (2002). The Haptica Walker. Retrieved December 1, 2002, from http:// www.haptica.com/whatwedo/walker.html

Harris, M. (1979). Cultural materialism: The struggle for a science of culture. New York: Vintage.

Hazan, H. (1994). Old age: Constructions and deconstructions. Cambridge, England: Cambridge University Press.

Hirsch, T., Forlizzi, J., Hyder, E., Goetz, J., Stroback, J., \& Kurtz, C. (2000). The ELDeR Project: Social and emotional factors in the design of eldercare technologies. Proceedings of the CUU 2000 Conference on Universal Usability. New York: ACM.

Industrial Design Society of America. (2002). IDSA home. Retrieved December 1, 2002, from http://www.idsa.org.

Kawamura, K., Pack, R., Bishay, M., \& Iskarous, T. (1996). Design philosophy for service robots. Robotics and Autonomous Systems, 18, 109-116.

Lankenau, A., \& Röfer, T. (2001, March). A versatile and safe mobility assistant. IEEE Robotics and Automation Magazine, 8, 29-37.

Lawton, M. P. (1982). Competence, environmental press, and the adaptation of older people. In M. P. Lawton, P. G. Windley, \& T. O. Byerts (Eds.), Aging and the environment: Theoretical approaches (pp. 5-16). New York: Springer.

Living at Home. (2002). Interviews with staff, Living at Home Program. Pittsburgh, PA: University of Pittsburgh Medical Center.

Mann, W. C., Hurren, D., Tomita, M., \& Charvat, B. (1995). An analysis of problems with walkers encountered by elderly persons. Physical \& Occupational Therapy in Geriatrics, 13(1/2), 1-23.

Marcoux, J.-S. (2001). The "Casser Maison" ritual: Constructing the self by emptying the home. Journal of Material Culture, 6, 213-235. 
Margolin, V. (1997). Getting to know the user. Design Studies, 18, 227-235.

Mazo, M. (2001, March). An integral system for assisted mobility. IEEE Robotics and Automation Magazine, 8, 46-56.

McCormack, M., \& Forlizzi, J. (2000). Listening to user experience: Integrating technology with proactive wellness management. Proceedings of the PDC 2000 Participatory Design Conference. Palo Alto, CA: CPSR.

Michelson, W., \& Tepperman, M. (2003). Focus on home: What time-use data can tell us about caregiving to adults. Journal of Social Issues, 59, 591-610.

Morris, A., Donamukkala, R., Kapuria, A., Steinfeld, A., Talbot-Matthews, J., Dunbar-Jacob, J., et al. (2002). A robotic walker that provides guidance [White Paper]. Retrieved December 1, 2002, from http://www-2.cs.cmu.edu/ thrun/papers/ thrun.robo-walker.html

MOVAID. (2002). MOVAID. Retrieved December 1, 2002, from http://www- arts. sssup.it/research/projects/MOVAID/default.htm

Mynatt, E. D., Essa, I., \& Rogers, W. (2000). Increasing the opportunities for aging in place. Proceedings of the CUU 2000 Conference on Universal Usability. New York: ACM.

Nardi, B. A., \& O’Day, V. L. (1999). Information ecologies: Using technology with heart. Cambridge, MA: MIT Press.

National Aging Information Center. (1989). Limitations in activities of daily living among the elderly [White Paper]. Retrieved December 1, 2002, from http://www.aoa.gov/aoa/stats/adllimits/httoc.htm

NavChair. (2002). The NavChair: An assistive navigation system for wheelchairs based upon Mobile Robot Obstacle Avoidance. Retrieved December 1, 2002, from http:// www-personal.engin.umich.edu/ johannb/navchair.htm

Netting, R. (1986). Cultural ecology (2nd ed.). Prospect Heights, IL: Waveland.

Norman, D. A. (1990). The design of everyday things. New York: Basic Books.

Prassler, E., Scholz, J., \& Fiorini, P. (2001, March). A robotic wheelchair for crowded public environments. IEEE Robotics and Automation Magazine, 8, 38-45.

RAID Workstation. (2002). RAID Workstation. Retrieved December 1, 2002, from http://www.oxim.co.uk/std.html\#RAID

RAIL. (2002). RAIL. Robotic Aid to Independent Living. Retrieved December 1, 2002, from http://www.robotics.lu.se/Robotics/research/projects/RAIL/RAIL.html

Salvador, T., Bell, G., \& Anderson, K. (1999). Design ethnography. Design Management Journal, 10(4), 35-41.

Scherer, M.J., \& Galvin, J. C. (1994). Matching people with technology. Rehabilitation Management, 7(2), 128-130.

Schraft, R. D., Schaeffer, C., \& May, T. (1998). Care-O-bot ${ }^{\mathrm{TM}}$ : The concept of a system for assisting elderly or disabled persons in home environments. Proceedings of the 24th IEEE IECON, Vol. 4. Aechen, Germany: IEEE.

Silverman, P. (1987). Community settings. In P. Silverman (Ed.), The elderly as modern pioneers (pp. 234-262). Bloomington: Indiana University Press.

Universal Design Principles. (2002). The Center for Universal Design-What is Universal Design? Retrieved September 1, 2003, from http://www.desugb/ncsu.edu: 8120/cud/univ_design/princ_overview.htm 
U.S. Census. (2000). Census Bureau Homepage. Retrieved September 1, 2003, from http://www.census.gov

Ward, R. A., La Gory, M., \& Sherman, S. R. (1988). The environment for aging. Tuscaloosa: University of Alabama Press.

Wheelesley. (2002). Wheelesley: Development of a Robotic Wheelchair System. Retrieved December 1, 2002, from http://www.ai.mit.edu/peole/holly/ wheelesley/ 